\title{
Current Situation and Management Innovation of Legal Consciousness in the Countryside
}

\author{
Yuan XIN ${ }^{1, a}$, Quan-Yi LI',b \\ ${ }^{1}$ Law and Political Science Department, North China Electric Power University, China \\ ${ }^{2}$ Law and Political Science Department, North China Electric Power University, China \\ ayuanxinsun123@126.com, 'rlanhudie1230123@163.com
}

Keywords: Social management innovation, Countryside, Legal consciousness, From top to bottom, Franco-prussian, Spirit of the law.

\begin{abstract}
We use questionnaires, field surveys, interviews and other ways to inspection the Current situation of Legal Consciousness in the Countryside, and, we found the following questions: All kinds of the franco-prussian work launched hotly, however, Legal consciousness did not come up to standards in the countryside, and the franco-prussian is too formal to be carried out, which makes the process of law develops slowly. Therefore, the government should innovative the ways of franco-prussian, and advocate the spirit of the law, and instill the real connotation and spirit of the law.
\end{abstract}

\section{Introduction}

Review of China's legal history, after 60 years of wind and rain, China opened a way to the success of the construction of socialism with Chinese characteristics. Objective, it is true that China is striding ahead on the path of the construction of the rule of law, also have made great achievements, but all sorts of problems also gradually highlights, obstacles on the road to development of law.

Promoting the construction of the rule of law includes two sides. On the one hand, it depends on the leading class. In the other words, it is promoted by the state power from top to bottom .On the other hand, a law enlightenment can make people really realize the importance of law, in that we can complete our legal system from top to bottom and promote the process of the rule of law . In practice, we pay more attention to the former. Government's work of popularizing the knowledge of law goes in full swing. All kinds of forms of propaganda emerge one after another. It seems that the work of improving public's legal consciousness from top to bottom does well. In fact, it didn't. People's legal consciousnesses haven't reach to an excepted standard. If we take government as a teacher, the public as students, the true situation is that the teachers are teaching in excitement, while students turn blind eyes to it. We focus on the work of government, but perhaps we pay little attention to enhance the people's quality of the law effectively. In fact this disconnects cause to the waste of resource and didn't have a good effect on popularizing the knowledge of law.

\section{Investigation of the present situation of rural legal consciousness}

\section{The legal consciousness of rural residents is weak}

In China ten social classes, the legal consciousness of rural residents is the most weak. Through in-depth investigation to the rural areas, we learned the truth about the rural legal construction. The questionnaire is a common way to acquire the condition of the people nevertheless, it gets more difficult in the countryside, excluding some villagers unwilling to fill out the case, more and more people know little about the meaning of the questions, low literacy may be one of the two elements that make it so stuff, but it also reflects the rural residents lack the basic knowledge of law. And only turn to the village committee for help when it appears the dispute, seldom do they recognize that a neutral judicial trial is the best way to solve all kinds of disputes to protect their legitimate rights and interests. Besides, Rights consciousness and more of less the idea of a thing also 
profoundly affected the daily lives of rural residents. What's more, for feeling prevalent in the ideas of the people does not trust law, in the questionnaire, it is widely believed that the law is aimed at ordinary people. Power and money oriented concept makes people feel very helpless. This is perhaps a common disadvantage in Chinese society, but still reflects the law seemed very distant from the agricultural population. However, we also very pleased to see that most people still have confidence and passion for the prospect of rule of law.

\section{No law propaganda work}

On whether the village has the law propaganda work, we heard many different voices. For the villagers all show the vague expression, obviously, the village committee put a little attention in law propaganda work, or even it has never been done. But via the interviewing to the village chief, rural law is mentioned in the village very often and pamphlets of the relevant laws were handed out among villagers. But we can't find clues about the work. Through the roster of village cadres, we can find that the cultural level of the village committee members are very low (elementary school or middle school level), individual quality is not too high, their understanding of the law is almost blank. It is hard to imagine that such village cadres can carry out the franco-prussian in the village. After the visiting of several areas, we find the rural situation is essentially the same, official rhetoric and reality is very biased. Saying without action maybe is the key of the problem. A passage from a villager is impressing, roughly mean that the policy is perfect, but it is another case when put it into reality. However good the implement plan are, if it can't carry out, then everything is in vain. The dissemination work of our government always carry out with a bang, and we, get more information on this matter from the news media, but we never experience it. Of course, there must be some places did very well, but according to our survey in rural areas, the franco-prussian work need improving.

\section{The reasons of the problems}

\section{The work of franco-prussian is too formal}

Form of government law and the law propaganda are not enough. In 1985, our country started the first legal work, and then implemented the franco-prussian plan for five years, and accompanied by a large number of law to cater to the economic and social development. In this background, the rural areas of the franco-prussian has gone through a journey of more than ten years of work, however, the franco-prussian took little effect, mostly because the law propaganda is officials, which is "showy" and formalistic. Village officials tend to simply put a law or law on the blackboard in village committee, or a broadcast on the radio, or send to the families round, or even don't work on it. It is unlikely to achieve the desired effect, much less do they make the broad masses of peasants and cadres enhance the understanding of the low in a short time. As the franco-prussian work is a long-term and arduous task, we need to spend more time and cost. Legal services provided by the Government is currently not well meet the needs of farmers at present, which is not simply reflect the effectiveness of the government should act.

\section{Tired of litigation}

In a conversation with rural residents, we noticed a widespread phenomenon, many villagers are dissatisfied with the director of the village the village Party branch secretary, such as village director of things, their relatives and family in the village is relatively strong, the villagers to the village cadres these behaviors have chosen silence and silence. Endurance is Chinese traditional service character, in the face of a dispute, more and more people choose to bear a lawsuit is not. Of course, bear down sometimes can better solve the disputes, but in the public to participate in the national management in this regard, the bear is a kind of negative attitude. Endurance is bound to 
lead people disregard for social affairs, the objective is not conducive to the construction of rule of law. Popularizing law so as to improve the legal consciousness of people is to let the people know how to defend their rights by legal, but if this endurance has been ingrained in the hearts of the people, even to understand the legal knowledge to also be of no avail.

\section{The lack of legal sense of trust}

The farmer is the most simple; the way to express feelings is the most direct. Perhaps the farmers of the law have been innocent, naive belief, but gradually they find it difficult to see their own interests from the law, so the attitude of the law was changed, if the cost of law-abiding than their vital interests, they will find other ways to solve the problem. The law did not really for the farmers to positive feelings, and it was not easy to win their trust and identity. If the lack of basic legal sense of trust, then they will think that learning the law is not necessary, and thus the loss of power to study law, this is equal to the loss of the object for the rural law popularization work, make the law more difficult. On the contrary, if the increase of farmers' confidence to laws, can greatly reduce the construction of rule of law in resistance.

\section{How to improve rural legal consciousness}

\section{Extensive public participation}

The current situation of rural legal consciousness is not optimistic, push forward the process of rule of law in the countryside to go15, law is still the key. We have been concerned about the government by law, but also referred to the law popularization work of formal and cannot achieve the desired results in the preamble, the formal way of working in China is already widespread, want to change is not a short duration of time of the work, this one will involve system reform, make change the formal law even more difficult, so here only talk about the specific should popularize what. Promoting the rule of law is another way through legal enlightenment made people realize the importance of the law from the Shangri to improve China's legal system, if the government's "law to send home", "sending law to the countryside" behavior is the embodiment of the will of the government, then rely on the citizen law consciousness awakening the movement is reflected the consciousness of the masses. The nature of these two ways is different. The top-down legal movement is more like the infiltration of public authority, some substantive law eagerly instilled in most of the other members of the society, which is obviously at the expense of all members of society to follow the rule of law are entitled to equal participation right, this method cannot make the social development by leaps and bounds. Only the broad public participation can reflect the will of the people, the construction of the rule of law has the vigor.

\section{Instill the real connotation and spirit of the law.}

Now the government legal work will be more inclined to the relevant law accurate, objective knowledge to the public is the only legal knowledge external perspective. Communication is essentially only with legal knowledge to strengthen the law for the social norm function. The goal should not be limited to the dissemination of legal knowledge, but more efforts should be made to enhance to publicize the spirit of the law, the legal spirit win support among the people. The law is the product of national will, since it is the society from within, and why from the outside and inside of the society. But there seems to be cycle, with the rural areas as an example, the rural residents' awareness of the law, and even do not have the basic knowledge of law, if the government does not perform the legal work that rural residents will never be able to get the law related education, and talk about what the law by the social endogenous. Therefore, the rural rule of law in the process of government legal work is still the foundation work, but its nature should be changed, namely the law not only to carry out the specific legal provisions and the inculcation of legal knowledge, basic 
is the requirement of the spirit of the law of understanding, understanding of the value of law, the law of emotion cultivation, set up the law will exercise and the law faith. Question of rural residents lack of trust on law and hinder the process of rule of law of endurance, but also related with the spirit of the law. The law is to rely on the coercive force of the state to achieve, but "one only by national force to carry out the law, is the theory on justice, also will certainly fail." The law should be the combination of the spirit body, only as the crystallization and carrier of spirit, the law can be truly belonged to the people. When the government's legal with the real connotation of law and spirit, rural residents can we deeply realize the importance of law, can be as a belief in law, which the law, legal consciousness and promote the rule of law process fundamentally.

\section{Conclusion}

Through investigation, we found that the level of law is low in the countryside, and there is no the work of Franco-Prussian. The reason is that the work of franco-prussian is too formal, and villagers is tired of litigation and is lack of legal sense of trust. Therefore, the government should innovative the ways of franco-prussian, and advocate the spirit of the law, and instill the real connotation and spirit of the law.

\section{Acknowledgment}

This research is supported by Investigation of ordinary citizens' legal consciousness present situation. (20132078)

\section{References}

[1] Hongyu Liu. Legal Faith Discussion[J]. People's Tribune. 2011(35)87.

[2] Ruifang Qiao. Concept Interpretation of Justice in Legal Procedure [J]. People's Tribune.2012.(12):122.

[3] Shaofeng Chen. Thinking about legal services in rural areas as the government. Academic Forum, NO.11,2011 (Cumulatively NO.250).

[4] Bo Wang. Spirit of the law. Legal System and Society.2011(35).

[5] Xiao Song. The paradox of the Franco-Prussian. Law and Social Development.2009(2).

[6] Li Su. The rule of law and local resources [M]. Beijing: China university of political science and law press, 1996(10). 